\title{
Hydraulic Hitch Systems of 900t Tyre Hosting Girder Machine Modeling and Simulation Analysis Based On SIMULINKIADAMS
}

\author{
Chen Yongqing ${ }^{1, a}$, Liu Weilang ${ }^{2, b}$ \\ College of Mechanical \& Power Engineering Of China Three Gorges University, \\ Yichang, Hubei Province, China \\ achenyq@126.com, 'blwlhuiyi@163.com
}

Keywords: tyre hosting girder machine; ADAMS/Hydraulics; hydraulic suspension system

\begin{abstract}
Hydraulic suspension is a common way to support 900t Tyre Hosting Girder Machine. In this paper, the hydraulic suspension system modeling is established under ADAMS/Hydraulics environment. Dynamics simulation analysis is performed on two kinds of road, Class of B and C. Comparing the displacement and the acceleration of trolley at the centroid. With the curve processing function to get the RMS value of acceleration, thereby obtaining the coefficient of dynamic load on the corresponding road. Providing reference for the designing and studying of the TYRE Hosting Girder Machine’s hydraulic suspension system.
\end{abstract}

\section{Introduction}

Tyre Hosting Girder Machine is the use of multi-axis tire of walking and heavy lifting machine, it is usually used to complete box girder lifting, carrying, walking, etc in the beam field. The force structure of the Tyre Hosting Girder Machine is formed by the main beam and leg structures. Traveling four wheeled trolley as a four-point anchor. In order to achieve a balanced force of the main frame structure, consistent with the requirements of the four-point anchor force. Hosting Girder Machine walking slow, have large weight and high security requirements.

\section{Establishing the hydraulic suspension system in ADAMS}

Before working, the pressure source provide oil to the system to ensure that each cylinder extend the same length. At the beginning of the work, the hydraulic oil source stops, all hydraulic suspension cylinders are connected and have the same pressure.
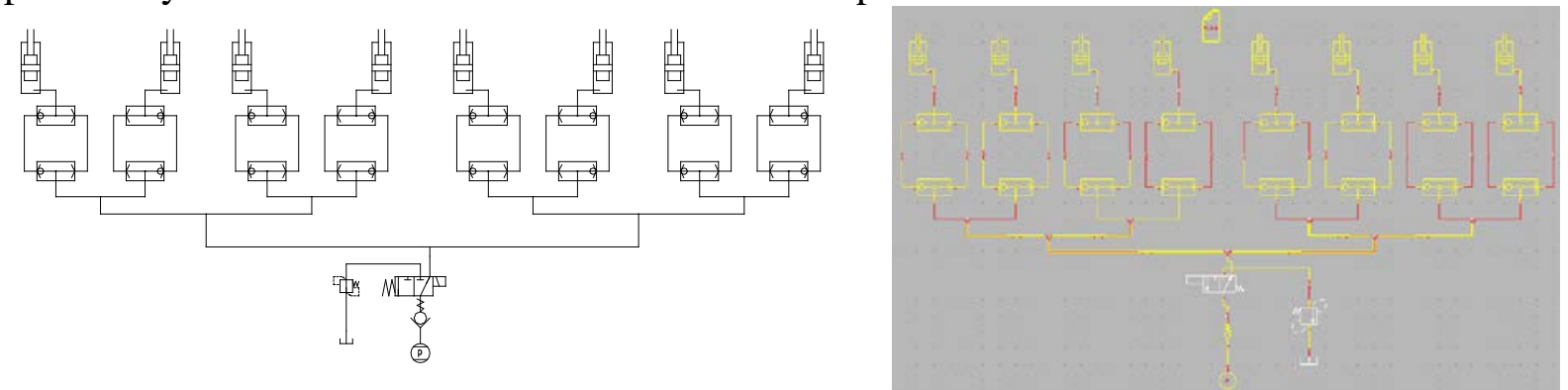

Fig.1 Hydraulic model in ADAMS

This hydraulic suspension system is particularly suitable for heavy duty vehicle.

It has the following advantages and disadvantages:

\begin{tabular}{|l|l|}
\hline \multirow{4}{*}{ Advantage } & $\begin{array}{l}\text { 1. The load is evenly distributed on each axle, and can automatically adjust the load of each } \\
\text { axis. }\end{array}$ \\
\cline { 2 - 3 } & 2. Each cylinder connected, it can prevent the occurrence of rollover \\
\cline { 2 - 3 } & 3. Can easily replace and overhaul tire in a time \\
\cline { 2 - 3 } Disadvantage & 4.Hydraulic line operation can be prevented from cracking \\
\hline & 1. Cylinder pressure, temperature rises fast \\
\cline { 2 - 3 } & 2. Hydraulic oil have energy loss in the flow process \\
\cline { 2 - 3 } & 3. Hydraulic oil can not compressible, vehicle stability is poor \\
\hline
\end{tabular}




\section{Establishing the simulation model of walking and support system}

1. Establish the mechanical system model

The size of TYRE Hosting Girder Machine is huge, and the structure is complex. So, the model is simplified. Selecting walking and support system as modeling and simulation object. Establish mechanical system model of trolley walking and supporting system.

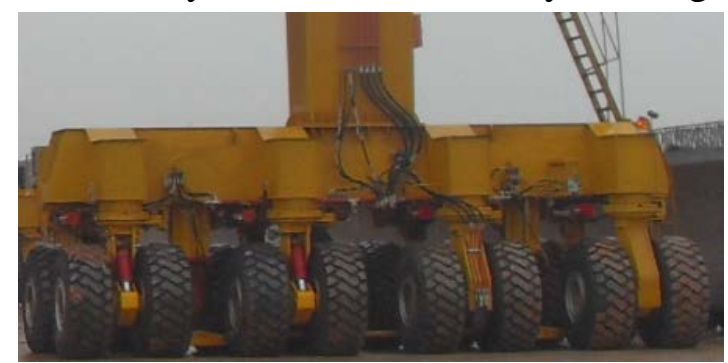

Fig2. Walking and support system physical map

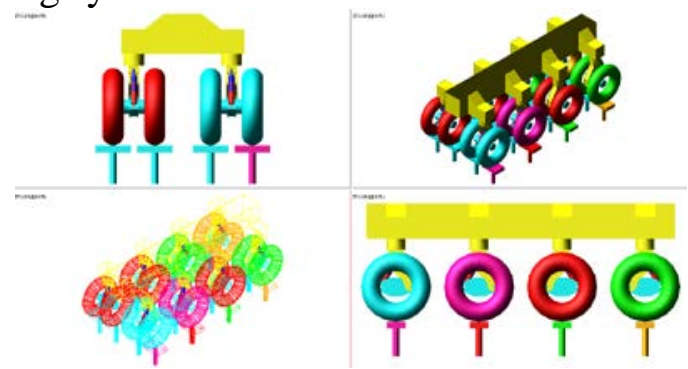

Fig3. Walking support system mechanical model

2. Establish the hydraulic system model

The weight of the whole hosting girder machine is 560t and the box girder is 900t. The total weight of all tires and Wheel Axle and driving part is 120t. The inner diameter of piston cylinder is $150 \mathrm{~mm}$.

The supporting force of each walking support is:

$$
F=\frac{560+900-120}{4 \times 8}=41.875 t
$$

The carrying capacity of each suspension piston-cylinder is:

$$
F_{1}=\frac{F \times L_{d}}{L_{b} \sin (\alpha+\beta)}=\frac{41.875 \times 480}{1080 \times \sin (51)}=24 t
$$

The pressure of each hydraulic cylinder is:

$$
P=\frac{F_{1}}{S}=\frac{F_{1}}{\pi(150 / 2)^{2}}=\frac{2.4 \times 10^{2} \times 10^{3}}{\pi(150 / 2)^{2}}=13.5 \mathrm{MPa}
$$

$F_{1}$ - Cylinder The external force of cylinder;

$P \quad$ - Hydraulic oil The pressure of hydraulic oil;

$S$ - The effective area of cylinder.

The hydraulic cylinders connect with the mechanical system by two I-Marker and J-Marker which correspond to two Marker point in the mechanical system. Mechanical systems and hydraulic systems can complete the establishment of a virtual prototype at the same interface and make simulation and analysis at the same time.

3. Input motion incentive

After the establishment of the mechanical systems and hydraulic systems, we should define the motion incentive. Choose selection of $\mathrm{B}$ and $\mathrm{C}$ Class of road roughness as a function of input motion. Change the power spectral density from the frequency domain model into a time domain model. We will use the same axle road excitation after the simplified of two wheels on the same axle, two axes on the adjacent axis analysis according to the correlation of the road surface, the input locus behind the wheel and front the wheel is the same, only a certain time lag exists.

The lag time $t^{\prime}$ is

$$
t^{\prime}=\frac{l}{v}=\frac{2.6}{0.28}=9.2 \mathrm{~s}
$$

\section{$l \quad$ - Front and rear tread}

So, the speed is $0.28 \mathrm{~m} / \mathrm{s}$, using SIMULINK to establish random grade road left and right wheel input simulation model. As shown in fig 4 , we can get all incentive about all wheels.

Set simulation time of SIMULINK is 60 s, the lag time $t^{\prime}=9.2 \mathrm{~s}$. In order to ensure all the wheels on the rough road when the time-domain analysis is taking, we select simulated curve when the 
time is 30s after 27.6s as road incentive into the ADAMS. So, we can get the incentive about left and right wheels for B and C Class road, the corresponding data points can be obtained from Fig 4.

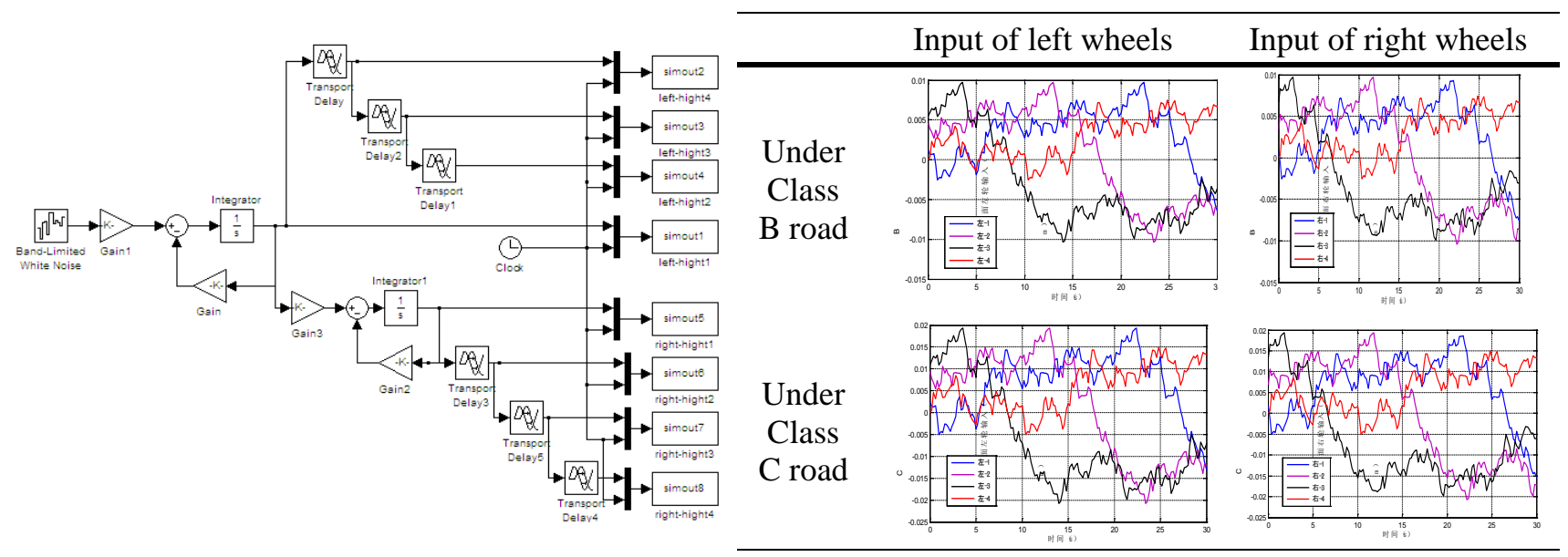

Fig4. Left and right wheel Simulation Model on the random road

\section{Simulation analysis on hydraulic hitch system of hosting girder machine}

After the establishment of the mechanical system model and hydraulic system model and the input of the motion incentive, dynamics simulation can be doing on the walking support system model. Observation and studies on the dynamic load when it's motion on two different Class road surface of B and C, we can get the corresponding dynamic load factor.

Setting simulation parameters.

According to MDEL900 Tyre Hosting Girder Machine work requirements and the above analysis, we can get simulation parameters of hydraulic suspension walking support system

\begin{tabular}{|c|c|c|c|c|c|c|c|}
\hline Name & Symbol & Numerical & Unit & Name & Symbol & Numerical & Unit \\
\hline $\begin{array}{l}\text { Cylinder's inner } \\
\text { diameter }\end{array}$ & $D$ & 160 & $\mathrm{~mm}$ & Tire inflation pressure & $P 1$ & 0.6 & Мра \\
\hline $\begin{array}{l}\text { Plunger's outer } \\
\text { diameter }\end{array}$ & $d$ & 150 & $\mathrm{~mm}$ & $\begin{array}{c}\text { Flow damping } \\
\text { coefficient }\end{array}$ & $C_{Z}$ & 0.62 & - \\
\hline Piston cylinder stroke & $L$ & \pm 150 & $\mathrm{~mm}$ & Ambient temperature & $T_{0}$ & 293.15 & K \\
\hline $\begin{array}{l}\text { Piston cylinder'sinitial } \\
\text { pressure }\end{array}$ & $P_{0}$ & 13.5 & Мра & $\begin{array}{l}\text { Initial simulation } \\
\text { temperature }\end{array}$ & $T$ & 293.15 & K \\
\hline Fluid density & $\rho$ & 860 & $\mathrm{~kg} / \mathrm{m}^{3}$ & $\begin{array}{l}\text { Connecting pipe inner } \\
\text { diameter }\end{array}$ & $d_{1}$ & 10 & $\mathrm{~mm}$ \\
\hline Supporting total load & $M_{1}$ & 335 & $\mathrm{t}$ & Simulation time & $t$ & 30 & s \\
\hline Non-supporting load & $M_{2}$ & 40 & $\mathrm{t}$ & Simulation step & $\Delta t$ & 0.2 & $\mathrm{~s}$ \\
\hline Tire stiffness & $k$ & $3 \times 10^{6}$ & $\mathrm{~N} / \mathrm{M}$ & & & & \\
\hline
\end{tabular}

Enter incentive about left and right wheels for B and C Class road (Fig.5) in ADAMS for simulation. 


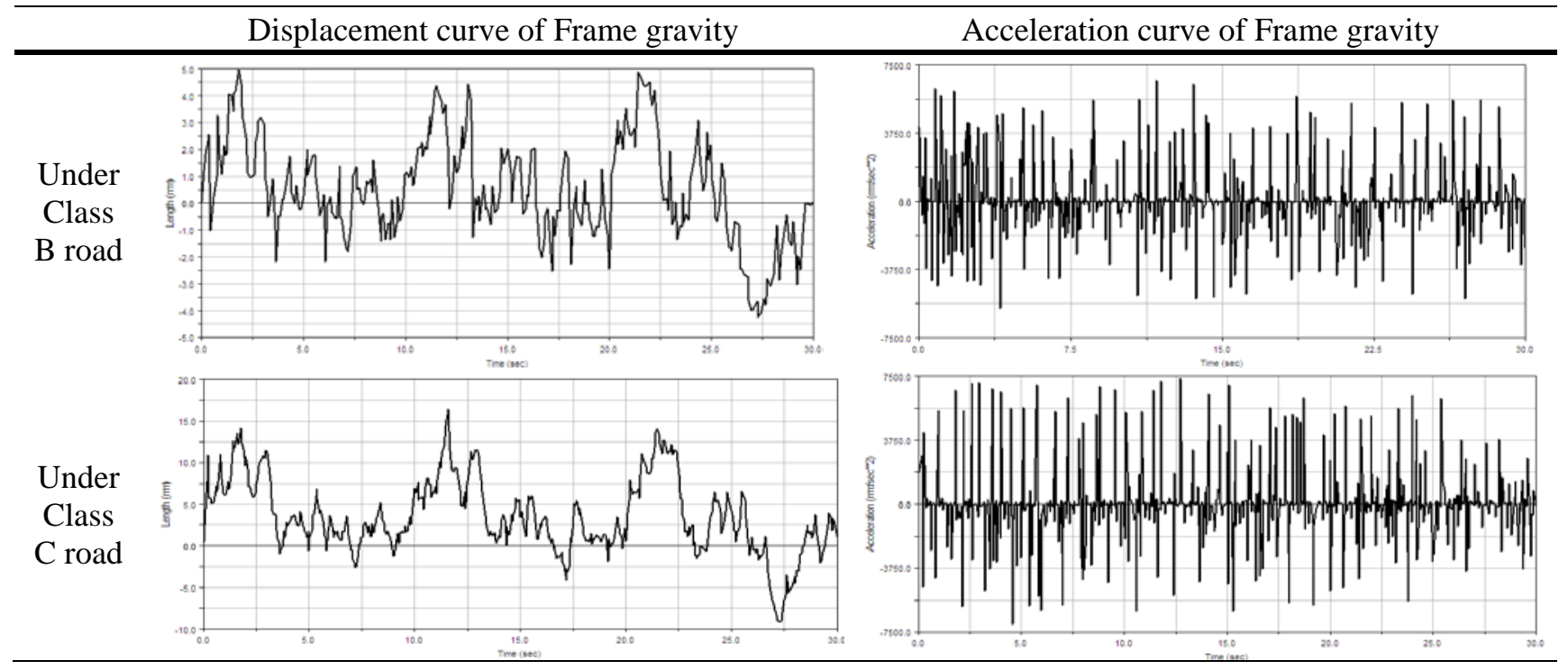

Statistical results are as follows:

\begin{tabular}{cccccccc}
\hline & $\mathrm{X}$ & $\mathrm{Y}$ & Slope & Min & Max & Avq & RMS \\
\hline $\begin{array}{c}\text { Gravity displacement under } \\
\quad \text { Class B road }\end{array}$ & 29.2 & -3.0196 & 10.2735 & -4.2566 & 4.9728 & 0.5407 & 1.9923 \\
$\begin{array}{c}\text { Gravity displacement under } \\
\quad \text { Class C road }\end{array}$ & 17.1798 & -4.1053 & 22.5402 & -9.0593 & 16.3357 & 3.517 & 5.6597 \\
$\begin{array}{c}\text { Gravity acceleration under } \\
\quad \text { Class B road } \\
\begin{array}{c}\text { Gravity acceleration } \\
\text { under Class C road }\end{array}\end{array}$ & 16.212 & -5102.746 & $-1.74 \mathrm{E}+05$ & -5849.971 & 6669.0214 & -4.3172 & 1244.4271 \\
\hline
\end{tabular}

Data Analysis:

(1) In the role of tires and support system delivered by road to slow down the trolley frame shock, frame volatility decreases compared to the magnitude of the road.

(2) On the Class C road, the frequency and amplitude of the frame acceleration curve's the peak values is lager. Therefore, the impact of the hydraulic system pressure is larger and ride suspension reduced.

\section{Conclusion}

In this paper, PRO/E software for the entire Hosting Girder Machine 3D model, improve and build their vertical vibration mechanical simulation models. Set up hydraulic suspension system modeling by binding kinetics simulation software ADAMS / Hydraulics. Select B, C two kinds of road construction road roughness index as a function of time-domain excitation input. Dynamic simulation model and analyze simulation results. Providing reference for the designing and studying of the TYRE Hosting Girder Machine’s hydraulic suspension system.

\section{References}

[1] Gui Zheng, Han Fei \& Zhang Haosu. An Analysis on the Effects of Road Roughness on Multi-axle Vehicle with Hydraulic Suspension [J]. Automotive Engineering, 2010,02:155-158.

[2] Thoresson M J, Uys P E, Els P S, et al. Efficient optimisation of a vehicle suspension system, using a gradient-based approximation method, Part 1: 32.Mathematical modelling[J]. Mathematical and Computer Modelling, 2009, 50(9): 1421-1436. 
[3] Fischer D, Isermann R. Mechatronic semi-active and active vehicle suspensions[J]. Control Engineering Practice, 2004, 12(11): 1353-1367.

[4] ADAMS/Hydraulics Help: Getting Started Using ADAM Hydraulics.

[5] MATLAB user's manual [M] 